\title{
THE APPLICATION OF COMPREHENSIVE COMMUNITY ECONOMIC ANALYSIS
}

\author{
Glen C. Pulver*
}

For the past 25 years, community economic development policy at the national, state, and local level has been characterized by the pursuit of panaceas. Time after time, single solutions have been offered as cures for local employment and income ills.

In the 1960s, agencies of federal and state governments encouraged and often fiananced the development of industrial parks and supportive infrastructure in cities and villages across the land. The hope was that manufacturing and assembly firms would be attracted to these sites, generating new employment and income. At the same time, others argued there was a critical need for the generation of income on the part of the disenfranchised. Community action programs were founded, based on the concept that collective efforts such as community development corporations by those who were the "have nots" would somehow lead to new sources of income and turn whole communities into "haves."

Community Economic Development in the 1970s might best be characterized by a push for financial incentives aimed at encouraging industrial development and/or the renovation of older city centers. Industrial revenue bonds and their accompanying lower interest rates and federal tax breaks became a part of nearly every state's incentives package aimed at luring business away from others. Federal grants and loans were combined with private funds to build glittering downtown shopping malls, convention centers, and housing complexes. Local governments were encouraged to organize special taxing districts. These districts used public funds to support private industrial and housing development with the promise of ultimate community fiscal benefit.

The attraction of high-tech industry has been the primary panacea proposed in the $1980 \mathrm{~s}$. Economic developers in states and communities throughout the nation have set their sights on attracting scientific laboratories and assembly plants associated with electronics or biogenetics. The expectation is that these "high-tech" operations will bring with them highly paid job opportunities and little environmental degredation. Since much has been written recently about the successful use of venture capital in financing "high-tech" expansions, governments are generating a wide spectrum of schemes to fill the supposed gaps in venture capital availability. Once again these incentives are aimed at outcompeting other locations.

\section{Shift in Economic Structure}

Throughout these shifts in community economic development program emphasis, the focus of most policy has been on creating mechanisms for attracting manufacturing plants. In the rush to attract employment generating opportunities, policy makers at the national, state, and local level have failed to recognize major structural changes in the U.S. economy. These changes have been so great as to blunt the effectiveness of a large portion of the economic initiatives of the past 25 years.

In the decade of the $1970 \mathrm{~s}$, only 5.5 percent of the employment growth in the United States was in the manufacturing sector [Economic Report of the President]. The absolute number of people employed in manufacturing is projected to remain close to current levels for many years in the future. Although there has been some decentralization leading to plant relocation and expansion, and many small business formations, there are limited opportunities for manufacturing employment growth in most communities.

*Professor of Agricultural Economics, University of Wisconsin-Madison. Presented at Southern Regional Science Association Annual Meeting, Orlando, Florida, May 3, 1984. 
Consequently, site vacancies dominate most of the industrial parks built in the $60 \mathrm{~s}$ and $70 \mathrm{~s}$.

Current efforts aimed at attracting the location of "high-tech" industries are apt to be equally ineffective. There are simply not enough employment opportunities generated by the "high-tech" sector to meet even a small portion of state and community desires. The nine "high-tech" industries actually experiencing more rapid growth than the average manufacturing firm in the 1970s constituted only 2.8 percent of total U.S. employment in 1982 [Browne, 1983].

The United States economy has become increasingly reliant upon the service sector as a primary employer. Employment in the goods producing sector has remained almost constant at slightly less than 30 million people for more than 60 years. During the same time period jobs in the service sector have grown from about 14 million to over 65 million today [National Commission on Employment Policy, 1982]. We are not simply "taking in one another's laundry." The tremendous growth in goods production efficiency has allowed communities to create substantial export industries in the service sector, including businesses such as insurance companies, banking centers, tourism complexes, computer service bureaus, and regional hospitals to cite a few. Add to this the continuing increase in family income share generated by dividends, interest, rents, social security, medicare, and medicaid. In 1980, approximately three out of ten dollars of family income was received from these sources [U.S. Dept. of Commerce, 1981]. It is easy to see that community economic development policy must be different in the $1980 \mathrm{~s}$ and $1990 \mathrm{~s}^{1}$

\section{Need for Comprehensive Community Economic Development Policy}

Policy makers at all levels should recognize the need for a more comprehensive look at the development options available at the local level. It is quite clear that major attention to the retention and perhaps attraction of goods producing industries continues to be necessary. Manufacturing, construction, farming and other natural resource exploitation remain fundamental sources of wealth and employment. What is equally evident is that the exploitation of all options rather than the pursuit of a singular panacea will be a requisite for community economic vitality in the future.

A comprehensive community economic development policy includes: (1) the historically dominant acquisition of businesses from outside the community; (2) capturing dollars already in the community and from those who can be enticed to visit; (3) encouraging the formation of new businesses; (4) helping existing businesses to become more efficient, thus assuring growth or extended survival; and (5) acquiring aids from broader units of government. It is imperative that those who are developing strategies aimed at implementing this policy remember the growing importance of employment in the service sector and income influence of the "silver-haired economic base." Specific strategies, undoubtedly different in nature, must be developed to influence location and growth of these important industries.

\section{Comprehensive Analysis}

Throughout the past 25-year period, regional scientists, geographers, sociologists and economists have generated and perfected a wide range of analytical tools-input-output analysis, location quotients, shiftshare, economic base, trade area capture, pull factors, population/employment, targeting and gravity models, to name a few. These tools are continually being used to study a specific hypothesis or problem, usually in a research mode. Increasingly, community economic analysis tools are being used for diagnosis. Local and regional planners, consultants, and community educators are applying community economic tools in seeking guidance for local policy makers. Unfortunately, the analytical devices are almost always used in isolation. That is, seldom are more than one of the tools used in any single study.

$\mathrm{Up}$ to this point, there is no well-defined system of comprehensive community economic analysis. No major effort has been made to combine the many individual tools into a collective set which can be used in diagnosing local problems and opportunities. There is no mechansim to tie together the total economic reality of a specific community's circumstance with all options for community economic development. Consequently, individual tools are used to look at single problems and local, state, and national policy makers continue to implement development strategies based upon panaceas and/or shared ignorance.

It is the responsibility of the regional scientists to knit together the many sophisticated analytical devices into a cohesive whole. They need to place these tools side by side in a rational, understandable, and useful manner so that those who use them can know which concern each addresses, how the answers 
they provide relate to each other, and which local concerns remain unaddressed. The ultimate users need some sense of which tool provides evidence of relevance to which policy option or development strategy.

For example, if a community is interested in developing strategies aimed at capturing more dollars, which specific community economic analysis tools will provide some insight about the specific opportunities? What combination of gravity models, trade area capture, location quotients, and population/ employment will be most revealing in communities of varying types and sizes? Conversely, if a community has little idea about where to begin in developing a comprehensive community economic development strategy, how can all the tools be fit together to begin to provide some idea about a starting point? Should it attempt a detailed input-output analysis? Is a simple economic base analysis appropriately revealing? Or, should the community attempt, more than likely pay for, a complete analysis using all available tools and hope something "shows up?"

\section{Computerizing Comprehensive Community Economic Analysis}

There have been two major roadblocks in operationalizing community economic analysis tools for wide use as local diagnostic devices: (1) data problems, and (2) massive "number crunching" requirements.

Many of the analytical tools require large, complex, detailed, and community-specific data sets if they are to yield results of value to local policy makers. Input-output analysis is a classic example of a tool requiring a tremendous amount of information on the sources of all inputs acquired by each industry in a community and the sectors to which all outputs are transferred. Data is costly to acquire, complex in its orientation, and seldom available from secondary sources. Researchers have been reluctant to generate representative data and define appropriate mechanisms for its transfer to specific cases. They recognize the many intellectual "warts" involved. Pragmatists have begun to generate model data sets and transfer mechanisms in order to compensate for the absence of community-specific data. This is not always done with proper caution.

Most of the tools require the massage of large quantities of numbers. Useful analysis requires very detailed information on factors such as employment, income, population and distance, often for many communities for purposes of comparison, or over several time periods to indicate directional shifts. The data massage itself is often accomplished through complex and lengthy formulae, sometimes requiring measures as sophisticated as indicators of statistical significance. The matching of large data sets with massive calculation algorithms has simply put the use of a wide spectrum of analytical tools beyond the reach of those with a primary interest in their direct application to local situations.

The introduction of high-speed, low-cost, user-friendly computing equipment presents an opportunity for a major leap forward in comprehensive community economic analysis. The computer has been of significant use in data gathering. True, garbage-in-garbage-out remains the rule, but the computer allows researchers from private consultant groups, universities and agencies of government, who already collect large amounts of data, the flexibility to present it in more usable fashion. For example, a state department of revenue which collects sales tax data may, because of computer accessability, be willing to generate community-specific data for even the smallest localities. The computer also provides the calculating capacity to allow the more "sure-footed" transfer of regional or national data sets to local conditions. In short, it may allow the reduction in the size of the "warts" because of the introduction of more controlling variables in the data adaptation.

In any event, the computer removes nearly all limitations to the development and application of comprehensive community economic analysis caused by massive number crunching requirements. It is precisely in the arena of meshing large data sets and massive calculation algorithms that the computer is at its best. If primary data is available or secondary data can be appropriately adjusted to fit, it is now possible to use any or all of the range of community economic analysis tools for the consideration of even the smallest of communities. Location quotients, trade area capture, shift-share and input-output analysis are no longer beyond the grasp of any but larger cities. All communities should now be able to compare their condition with that of "similar" localities.

Vital statistics will shift as years pass. The calculating mechansims need not. The computer makes it possible to bring together continuously shifting data sets and relatively fixed mathematical algorithms without concern for the volume of numbers or complexity of the calculations. Changes over time can 
become an analytical reality rather than just a dream for all.

The computer does not, however, provide the rational interface between community economic analysis and community economic development policy options. It only opens the door, but it is up to regional scientists to lead the way through it. The critical need is for the development of a clearly defined matrix which relates all elements of comprehensive community economic analysis to local problems and goals and which provides guidance in selecting the proper combination of strategies to implement a community specific comprehensive community economic development program. Without such a matrix, the computer is of limited use in pragmatic applications, and local policymakers are apt to continue pursuing single solutions.

\section{A Beginning}

Over the past few years a small group of community development economists at the University of Wisconsin-Madison has attempted to develop just such a comprehensive community economic analysis system. The effort was begun by carefully detailing all available analytical tools. Necessary data sets were catalogued and their availability established for Wisconsin communities of varying sizes. In addition, the level of computing power necessary to utilize each tool, and the difficulty of interpreting the results to local leaders were noted. At the same time a theoretical framework for examining relevant community economic policy options was developed [Pulver, 1979].

Testing of a crude but comprehensive matrix combining the analytical tools and policy options was then initiated in a number of Wisconsin communities. Industrial development corporation executives, chamber of commerce members, bankers, business leaders, local government officials, and other interested citizens are led through a series of analytical efforts. Shifts in the local economic base are compared with those at the state and national level. The employment and income characteristics of a specific community are compared with at least three similar communities and other standards of performance using tools such as gravity models, location quotients, trade area capture, and population/employment ratios. Options for development are studied using the tools at hand. Finally, the participants develop a comprehensive community economic development plan applicable to their community. These pragmatic tests continue as a mechanism to improve the quality of the analytical matrix.

In 1982, the University of Wisconsin group received financial support from the North Central Rural Development Center to produce a manual describing the range of community economic analysis available. The manual specifies necessary data sets and potential sources [Hustedde, Pulver, Shaffer, 1984]. It also indicates how the tools might be used and their proper interpretation in diagnostic applications. At this point the manual is restricted primarily to those analytical tools for which useful data sets are readily available. Thus, it is not yet as comprehensive as it should be.

In the fall of 1983, the North Central Rural Development Center, the North Central Computer Institute and the University of Wisconsin provided expanded support for the computerization of the community economic analysis system described in the manual. The system is being developed on a large main-frame computer with large data management capacity. The plan is to create two major information sets. One will be analytical tool algorithms. The other, the large data sets which the computer can then join with the community economic analysis tools at the request of the operator. It is hoped that the operator might ultimately be an economic planner, private consultant, governmental official, community educator, or other representative of a community. At the push of a button, the operator will be able to choose analysis results from almost any other Wisconsin community for purposes of comparison. In the intermediate term, the system will provide for the distribution of the calculation algorithms via floppy disc use in microcomputers. It will be necessary to input data directly from printed materials. In the near future, the entire system will be automated. The tools for comprehensive community economic analysis and planning are at hand. The more pragmatic community tests are aimed at assuring reality.

\section{Summary}

There is little excuse to continue the single-solution approach which has characterized the past quarter century of community economic development policy in the United States. Regional economists now have the necessary computing power to help local leaders tie the full range of analytical tools and the entire array of policy options into a clear and comprehensive plan of action aimed at solving local problems 
and achieving local goals. Although the tools are at hand, little will be accomplished until the critical shifts in economic structure are recognized. No longer will the sole reliance on policy oriented to stimulating the goods producing sector reap sufficient dividends in the form of increased jobs and income. The rising influence of the service sector as a basic employer and transfer payments, rents, interest, and dividends as sources of personal income must be reckoned with. So, too, must be the increased importance of the formation of new and the expansion of existing businesses as fundamental job generators.

The opportunity to combine the wide array of analytical tools and development strategies into a rational development policy matrix is at hand. Such a system must be comprehensive, understandable, uncomplicated, and produce reasonably correct estimates of current behavior, problems and opportunities if it is to be useful in diagnosis at the local level. The challenge to regional scientists is to take the many individual analytical tools and strategies which they have developed in years past and combine them into a comprehensive community economic analysis system which works.

\section{FOOTNOTES}

${ }^{1}$ Since most of this income goes to those over 65 years of age, Shaffer refers to them as the "silver-haired economic base" [Shaffer, 1981].

\section{REFERENCES}

Browne, Lynn E. "Can High Tech Save the Great Lakes States?" New England Economic Review, Federal Reserve Bank of Boston, Nov./Dec., 1983.

Hustedde, Ron, Glen Pulver and Ron Shaffer. Community Economic Analysis Manual, unpublished draft, Department of Agricultural Economics, College of Agricultural and Life Sciences, University of Wisconsin-Madison, March, 1984.

Pulver, Glen C. "A Theoretical Framework for the Analysis of Community Economic Development Policy," Nonmetropolitan Industrial Growth and Community Change, Lexington Books, D.C. Heath and Company, 1979.

Shaffer, Ron. "The Silver Haired Economic Base," Community Economics Department of Agricultural Economics, College of Agricultural and Life Science, University of Wisconsin-Madison, January, 1981.

U.S. Department of Commerce, Bureau of Economic Analysis, Survey of Current Business, Vol. 61, No. 7, July, 1981. 